\title{
Análisis de la influencia filosófica hermética en La Gitanilla de Cervantes
}

Analysis of hermetic philosophical influence on La Gitanilla of Cervantes

\author{
Alisa Gladyševa ${ }^{1}$ \\ Universidad de Vilnius, Lituania
}

Recibido: 30.06 .2021

Aceptado: 24.08.2021

\section{Resumen}

Esta investigación está dedicada a la influencia filosófica hermética de la obra La gitanilla de Cervantes. Debido a muchos tipos diferentes de alegorías literarias que existen en los manuscritos del Siglo de Oro, este trabajo se centra en las alegorías intertextuales de la interpretación hermética a nivel de alegorías con juegos de palabras que están saturados en las obras de Cervantes. Además, este trabajo se centra en la falta de comprensión del contexto intertextual de filosofía hermética lo que lleva al problema de la determinación y, por lo tanto, a ignorarlas en las obras de Cervantes y especialmente en la obra La gitanilla.

Palabras clave: Cervantes, La gitanilla, alegoría, el Siglo de Oro, hermetismo.

\begin{abstract}
This research is dedicated to the hermetic philosophical influence of the work La gitanilla by Cervantes. Due to the many different types of literary allegories that exist in the Golden Age manuscripts, this work focuses on the intertextual allegories of hermetic interpretation
\end{abstract}

\footnotetext{
1 independent_vu_researcher@graduate.org
} https://orcid.org/0000-0001-7739-1714

Volumen 2. Número 1. Enero - Junio 2022 ISSN: 2745-0333 (En línea) 
at the allegorical level with puns that are saturated in the works of Cervantes. In addition, this work focuses on the lack of understanding of the intertextual context of hermetic philosophy, which leads to the problem of determination and, therefore, to ignore them in the works of Cervantes and especially in the work of La gitanilla.

Keywords:Cervantes, La gitanilla, allegory, the Golden Age, hermeticism.

Porque nada hay encubierto, que no haya de descubrirse; ni oculto, que no haya de saberse.

Lucas XII,2

\section{Introducción}

La filosofía hermética es uno de los más complicados temas del pensamiento del escritor y entrelazados con su talento para usar el lenguaje. Por ejemplo, usar significados secundarios, por ejemplo, alegorías y metáforas con los términos claves que se conocían como palabras herméticas en el Siglo de Oro, para indicar el significado hermético primario del contexto.

Es importante destacar que esta investigación se basa en las palabras del propio Cervantes, sin teorías hipotéticas. Y se apoya en las diversas investigaciones que fueron realizadas por otros investigadores. En razón, según Cervantes reverencia, adora y sigue solo a fray Luis de León (Cervantes:1967, 751), que fue un seguidor de la filosofía Hermética y la estaba enseñando en la Universidad de Salamanca. Además, en 1583 su discípulo Pedro Malón de Chaide simplemente en texto abierto escribió sobre preferencias filosóficas que se le enseñó en la Universidad de Salamanca. (Chaide:1603, 342.)

Es importante señalar que la filosofía hermética en la época medieval y en la Edad de Oro no tenía nada de magia y brujería, como se hizo más tarde. Se basaba en la antigua poesía griega que se tradujo en los monasterios de ese período o antes. 
Desde el siglo XII existen manuscritos de filosofía hermética escritos por monjes en España. La resurrección de Dios se describe alegóricamente como la recepción del oro después de todas las etapas de descomposición del metal. El logro de la piedra filosófica y sus propiedades curativas fueron referidas como un regalo de Dios para curar no solo los cuerpos, sino también las almas.

La comprensión intertextual de la filosofia hermética necesita la competencia del lector que subyace no solo en el conocimiento del lenguaje literal, sino competente del ambiente cultural, filosófico e histórico del Siglo de Oro.

El objetivo de esta investigación no es desvelar si Cervantes era un verdadero adepto de la filosofía hermética o era escéptico al respecto. Pero sus alegorías y metáforas herméticas filosóficas son obvias. En razón no se trata de interpretación de palabras al azar, sino que la filosofía de Trismegisto tenía sus propias reglas y estudios, por ej., nigredo, albedo, rubedo, que se siguen en una fila. Entonces encontrarlo en la obra de Cervantes no es una coincidencia.

La influencia filosófica en los textos de los escritores, dependía de su nivel de educación y la intención de ocultar algunos de sus pensamientos sobre eventos históricos o estudios filosóficos que estaban prohibidos en su tiempo. Especialmente, el uso de alegorías filosóficas herméticas fue la manera exitosa de mantenerse a salvo para los escritores contra la persecución de la Inquisición en el Siglo de Oro.

Es posible que Cervantes haya usado muchas alegorías para asegurar sus pensamientos no solo históricas, pero herméticas también. La gitanilla es un poema intertextual que se refiere a una época oscura en la que vivió Cervantes, especialmente a la segunda mitad del reinado de Felipe II.

La connotación contextual de las alegorías refleja implicaciones particulares del dominio de conocimiento específico de los escritores. 


\section{Metodología}

Es importante mencionar que una alegoría en realidad deriva del griego $\alpha \lambda \lambda o \varsigma$, allos, que se traduce como "otros" y $\alpha \gamma o \rho \varepsilon v \varepsilon l v$, agoreuein, que se traduce como "hablar en público", como derivación de la palabra latina de alegoría.

Es curioso que Dionisio Areopagita derive la alegoría de la analogía en realidad. "Con la ayuda de estas imágenes podemos elevarnos a cosas inmateriales desprovistas de imágenes, asumiendo que las semejanzas no se entienden en un sentido terrenal": (Dyonysious, 1955, p. 107).

En realidad, la alegoría como medio de expresión literario es una metáfora extendida que se refiere directamente a una cosa al mencionar otra y, lo que es más importante, puede proporcionar u oscurecer la claridad. Así, cuando una obra representa cualidades morales bíblicas, un fenómeno espiritual o de realidad expresado en un concepto de vida específico,

Importante, que una idea particular en un concepto simbólico con una persona $\mathrm{u}$ objeto significa otra persona u objeto, como concepto espiritual. Los principios, como las mejores alegorías se pueden encontrar en la Biblia hebrea, y en la Biblia, por ejemplo, la connotación más importante de las alegorías bíblicas es Dios y su espíritu eterno, fueron muy populares en los primeros tiempos cristianos, así como en la Edad Media hasta nuestros días y en adelante.

Se pueden encontrar alegorías extendidas en la Biblia, por ejemplo. en el Salmo 80, el arco iris como concordancia, el símbolo del crecimiento de la vid y que representa la conquista y el asentamiento de Israel de la Tierra Prometida, la Luz o como una alegoría de la eternidad y la existencia para siempre, una paloma que expresa el espíritu santo, la León está representado por el Rey. 


\section{Contexto}

\subsection{Parte teórica sobre la obra La gitanilla de Cervantes}

Cervantes escribió una serie de novelas que se publicaron en la colección de novelas 'Novelas ejemplares de entretenimiento honesto' en 1613 y presenta a los lectores variaciones sobre temas morales y sociales en estas novelas.

La obra La gitanilla es la más larga de las novelas ejemplares. Existe la opinión generalizada de que esta novela en particular tiene una trama muy simple, como muchas otras novelas con una historia de amor tan popular en la Edad de Oro. El tema se centra en las aventuras de Preciosa, una joven de gran belleza y de su amor, Don Juan de Cárcamo, vástago de una familia noble, que lo abandona todo para llevar una vida errante con la joven.

El lector solo necesita entender la cuestión social, como declaración de amor que Preciosa le hace a Andrés, en razón de que ella era una gitana y él un hombre de nobleza. La trama muestra el amor trascendental que tenían estos dos protagonistas, que al final a pesar de los problemas de clases sociales, están juntos.

La idea principal de La gitanilla es la diferencia entre las clases sociales, en particular la sociedad española y la comunidad gitana. Trata el amor entre dos jóvenes: el joven noble se enamora de la mujer en posiciones bajas. Representa una problemática social, espiritual, moral de nobleza, libertad y amor. Cervantes intenta ilustrar los rasgos nobles, a veces sus imperfecciones como imperfecciones de la alta sociedad y escribe mucho sobre el mundo bajo de los gitanos y su descripción. Muestra los estereotipos de los gitanos dentro de la sociedad española en ese momento.

En el texto también encontramos las reflexiones del narrador, que, obviamente, hacen referencia al pensamiento del propio autor sobre las cuestiones sociales de ese período, la historia y como podríamos entender más adelante sobre la filosofía hermética. 
Generalmente, La gitanilla es un texto en prosa, de carácter narrativo, con cronológico método narrativo, en razón empieza desde el principio de la historia. Estilísticamente predominan las oraciones complejas, que revelan un estilo cuidado y asequible usado con genialidad por Cervantes. Aunque intercalado con la presencia periódica de las composiciones poéticas, pero no hay división en capítulos.

El texto en prosa presenta un predominio general de las acciones, que actúan como el avance de la trama. Las composiciones poéticas no son solo el punto formal de La gitanilla, como se va conociendo, trae algunos no solo históricos, sino información filosófica mediante el uso de conceptos alegóricos. Por tanto, como se verá en el capítulo de resultados, las composiciones poéticas llevan pistas informativas en la realidad.

Además, es importante prestar más atención a la variación de la parte poética. Por ej. la primera composición poética es un romance dedicada a Santa Ana, madre de la Virgen María con connotación alegórica:

Árbol preciosísimo

que tardó en dar fruto...

(Cervantes, 2015, p. 57)

El segundo romance, dedicado a la reina Margarita también es informativo en el uso de contextos alegóricos:

Salió a misa de parida

la mayor reina de Europa...

(Cervantes, 2015, p. 60) 
La adivinación es composición poética contada por la gitanilla Preciosa y también tiene tendencia a la estructura de rima con connotación filosófica alegórica, como investigaremos en el capítulo de resultados:

- Hermosita, hermosita, La de las manos de plata,

(Cervantes, 2015, p. 71)

Atrayente es la composición poética de Andrés y Clemente, que cantan estancias de ocho versos:

Mira, Clemente, el estrellado velo

con que esta noche fría...

(Cervantes, 2015, p. 116)

La composición poética de Preciosa con una composición formada por ocho redondillas:

En esta empresa amorosa, donde el amor entretengo...

(Cervantes, 2015, p. 118)

\subsection{Parte teórica sobre la derivación de la influencia filosófica hermética en el Siglo de oro}

Gracias a las traducciones de los textos Corpus Hermeticum y Tabla de Esmeralda en el siglo XV (Stoops, 2016, p. 576), el hermetismo se convierte en la doctrina de los alquimistas europeos e influye en el desarrollo de la filosofía europea. Significa que fue bastante popular en la época medieval, y especialmente en España durante los siglos XV al XVII, por la familiaridad del tema en los círculos intelectuales españoles (Stoops, 2016, p. 575).

La enseñanza del hermetismo estaba oculta, abierta solo a los adeptos. Las connotaciones de las alegorías herméticas estaban ocultas en los mismos textos, no solo de personas, que no eran adeptos, sino también de la Inquisición. 
Algunas obras herméticas se conocieron antes en España, gracias a las obras del pseudoLulio.

Pseudo-Lulio lleva el nombre de Raimundo Lulio, quien vivió en el siglo XIII y fue conocido como filósofo y teólogo. El libro de Lulio El árbol del conocimiento fue reeditado en 1505 y es el más importante en el sentido de alegorías filosóficas con los principios básicos de cada ciencia que se conocían en la época medieval. Por ejemplo, los árboles metafóricos, donde el árbol materno representa la mariología y el árbol celeste representa la astrología. En su libro sexto de Llibre de meravelles (Lulio, 1900, p. 30) habla directamente de las alegorías herméticas, hay una disputa entre el hierro y la plata, y le da algunas connotaciones de alquimia, quiere decir que en la España medieval se conocía intertexto alquímico.

Pseudo-Lulio escribió varias obras herméticas, pero todas apócrifas. Se cree que el verdadero autor de la obra alquímica de pseudo-Lulio sería Ramón de Tàrrega, un rabino, judío convertido del siglo XIV llamado también como el "Ramón Llull de Tàrrega", era un frágil dominico. Libro de los secretos de la naturaleza y La quintaescencia se encuentran entre los más conocidos. Es interesante que estas obras fueran muy populares en España en ese período, por ej. la nueva investigación del Manuscrito Voynich da resultados seguros de que fue escrito en España y también tuvo la influencia de las obras de pseudo-Lulio (Gladyševa, 2020, p. 13).

Es importante señalar que las alegorías y metáforas herméticas son difíciles de reconocer, especialmente en las obras muy populares de escritores famosos. Las obras de Cervantes son tan populares, por lo tanto, es difícil para los lectores darse cuenta de que estas obras famosas tienen, además de las alegorías conocidas, como la bíblica, las significaciones históricas también tienen las alegorías herméticas más difíciles de entender simultáneamente. Según la obra de Sir John Harington Briefe Apologie de Poetrie con su traducción de Orlando Furioso (1591), describe las connotaciones de las alegorías y metáforas poéticas como significados misteriosos. 
El problema no es solo la falta de información de metáforas herméticas o debido a la variedad de significados, sino que muy a menudo en la Era de la Inquisición era popular usar alegorías de tipos absolutamente diferentes en una misma obra. (Castillo, 2005). Heinrich Khunrath, en su obra Amphitheatre Sapientiae Aeternae, identificó la Piedra Filosofal con Cristo, quien fue buscado en la época medieval por monjes católicos que estaban bien familiarizados con la filosofía hermética. (Khunrath, 2016, p. 1)

Generalmente, el análisis del significado de las alegorías herméticas y su simbolismo es muy especial y debe ser muy escrupuloso. En razón, se utiliza la sensibilidad religiosa y simbólica de las palabras y el análisis debe ser también adecuado.

Según Brown God and the Mystery in Words, la experiencia de comprensión de la alegoría bíblica es una comprensión intelectual de Dios, por lo tanto, su presencia es cercana al lector: "La metáfora en sí misma puede proporcionarnos una experiencia de presencia divina." (Brown, 2008, p. pág. 67) Además, el contexto de las alegorías podría tomarse como la fuente de un significado oculto de Dios. Por eso, Dios fue visto como "el último escritor de cada texto" (Ullén, 2001, p. 184).

Las alegorías existían como una concepción del simbolismo oculto. Según el libro Los límites de la interpretación de Umberto Eco: "El pensamiento hermético dice que nuestro lenguaje, cuanto más ambiguo y polivalente es, y utiliza símbolos y metáforas ..." (Eco, 1992, p. 30) Por lo tanto, el lenguaje de la filosofía hermética se basa en el simbolismo, por ejemplo, cuatro elementos como Aire, Fuego, Tierra, Agua. El sol significa el oro ordinario Mercurio significa el símbolo de la plata preparada para la obra. Saturno significa el símbolo del plomo. Venus significa el símbolo del cobre. Marte significa el símbolo del fierro. Luna es el Mercurio filosófico, plata preparada para la obra. Júpiter significa el símbolo del estaño. Es muy fascinante, que, la filosofía hermética usa los símbolos de diferentes animales y aves, como león, paloma, águilas, etc. Así como el nombre de las flores. (Poisson, p. 84) 
Según José Vallés Belenguer en su obra Alquimia en las metáforas de Cervantes, está seguro de que la mayor parte de las alegorías de Cervantes derivan del hermetismo como filosofía hermética (Belenguer, 4). En Don Quijote hay algunas alegorías herméticas, por ejemplo: "Ni todos los que se llaman caballeros lo son de todo en todo; que unos son de oro, otros de alquimia, y todos parecen caballeros; pero no todos pueden estar al toque de la piedra de la verdad" (Cervantes, 52).

Cervantes basándose exactamente en las alegorías de sus obras, utilizó la diferencia entre el significante y el significado para la asimilación y al mismo tiempo por la dificultad para comprender el contexto real por los diferentes significantes de un mismo significado.

Por eso Cervantes utilizó diferentes tipos de alegorías como históricas, filosóficas como los significantes. Este concepto ofrece una posibilidad especial de comprender las obras de Cervantes con una nueva interpretación. Sin embargo, esta investigación muestra algunos temas apócrifos de filosofía hermética que fueron utilizados por Cervantes en La gitanilla. Curiosamente, la investigadora Rosa María Stoops sugirió sin ninguna explicación completa que La gitanilla puede leerse como una obra filosófica hermética mediante la interpretación de la connotación del texto y sus alegorías con el concepto de comprensión de manera hermética: "Desde La gitanilla hasta La tía fingida, el lector emprende una jornada de descubrimiento de numerosos elementos ligados al dios Mercurio y a la gran obra. [...]" (Stoops, 2016, p. 581)

El hermetismo ya era conocido en España en la época medieval, debido a la influencia de los antiguos griegos que fueron conocedores de esta filosofía. Por ejemplo, algunos cánones fueron escritos en la Catedral de Burgo de Osma con ideas filosóficas sobre el hermetismo, los mismos escritos herméticos se encontraron en la Catedral de Toledo y en el Monasterio de San Lorenzo de El Escorial (Pérez, 213).

El hermetismo era conocido particularmente en Salamanca en el Siglo de Oro. El aspecto más importante es la lexicología hermética que he venido usando como alegoría. Según Stoops, 
Cervantes no solo estaba interesado en la filosofía hermética, sino que también era un verdadero conocedor de los textos herméticos, que se pueden descubrir en obras como $\mathrm{El}$ ingenioso Hidalgo Don Quijote de la Mancha y Las obras de Persiles y Sigismunda (Stoops, 2016, p. 581).

Fray Luis de León ciertamente tenía una conexión con el hermetismo, en razón llamado adepto de Hermes Trismegisto y agregó su genealogía a su De Civitate Dei (Byrne, 2012,p. 1). Existe alguna evidencia de que Fray Luis de León fue un seguidor de la filosofía Hermética y la estaba enseñando en la Universidad de Salamanca. Por ejemplo, en 1583 su discípulo Pedro Malón de Chaide simplemente en texto abierto escribió sobre preferencias filosóficas que se le enseñó en la Universidad de Salamanca:

Yo seguiré — escribe — en lo que digere, a los que mejor hablaron de esta materia, que son Hermes Trismegisto, Orfeo, Platón y Plotino....

(Chaide,1603, p. 342)

Fray Luis de León fue un gran catedrático de la Universidad de Salamanca, conocido y respetado por Cervantes. Es muy importante mencionar que Cervantes dedicó el texto del Libro VI de La Galatea a Fray Luis de León y el uso del lenguaje hermético reveló su habilidad:

En él cifro y recojo todo cuanto

he mostrado hasta aquí y he de mostraros:

fray Luis de León es el que digo,

a quien yo reverencio, adoro y sigo

(Cervantes, 1967, p. 751)

Cervantes quiere señalar el lugar predominante que le da a Fray Louis de León como su mentor y asegura que en él "cifra y recoge todo cuanto ha mostrado hasta aquí". Más de lo que indican que Fray Luis es como la clave de interpretación de sus propias obras (Alcántara Mejía, 1998, 73) 
Probablemente, podría ser una verdadera propina para suposición, que Cervantes utilizó la filosofía hermética. En razón, según Cervantes reverencia, adora y sigue solo a fray Luis de León (Cervantes:1967 Obras, 751), significa que sigue como adepto aceptando la enseñanza de la filosofía hermética.

Dos novelas de Cervantes tienen aproximadamente las mismas alegorías herméticas:

"Díjola que, a dos salidas al teatro lloverían minas de oro a cuestas, porque los príncipes de aquella edad eran como hechos de alquimia, que llegada al oro es oro, llegada al cobre, es cobre..."

(Cervantes, 1967, 648)

En la obra Los trabajos de Persiles y Sigismunda y también en la obra La tía fingida, incluyendo obviamente ciertas referencias a la alquimia, que es un concepto importante de la filosofía hermética:

Los extremeños, tienen de todo como boticarios, y de alquimia, que, si llega a plata, lo es, y si al cobre, cobre se queda.

(Cervantes, 1967, 648)

Como se desprende del texto de El viaje del Parnaso, Cervantes no deja dudas sobre su interés por la filosofía hermética, por lo que estaba utilizando el concepto principal de hermetismo como alegoría del mercurio que se menciona no solo como parte de la piedra filosófica, sino es el nombre alegórico del fundador del hermetismo en realidad,

En cuyo traje y ademán severo

vi de Mercurio al vivo la figura, de los fingidos dioses mensajero.

(Cervantes, 1967, 68) 
Otro argumento del interés de Cervantes por la filosofía hermética es el artículo Plantas en las obras de Cervantes, en el que los investigadores analizaron cuantitativamente las flores en todas las obras de Cervantes. Los resultados son asombrosos: hay 1.035 frases que contienen los nombres de 150 especies de plantas y se utilizan como figuras estilísticas para expresar alegorías simbólicas con connotaciones filosóficas.

Pero el estudio de las alegorías etnobotánicas incluyó solo los aspectos principales de la filosofía: de rosas o de palmas, por ej. el olivo es una alegoría bíblica de la paz que se utilizó en La Galatea, así como una rosa, que también se refiere a la Biblia como una alegoría del amor y la libertad: "Del campo hay y han sido mi amor; / rosas y jazmines son mis cadenas. "(Cervantes, 326v)

El lauro y guirnaldas son alegorías bíblicas de la victoria como en El laberinto del amor (Cervantes, 106 r) se utilizan con mucha frecuencia en sus obras.

Quizás Cervantes no en vano utilizó los nombres de las flores, según sus frases en La Galatea y El viaje del Parnaso, las alegorías tenían tendencias a la filosofía y sobre todo al conocimiento del hermetismo, que escondía en las alegorías de sus obras.

Además, conocía todos los nombres de las plantas y usaba especialmente las plantas que eran muy importantes en alquimia y que se usaban en hermetismo para una gran obra:

Ármate de tus versos luego, y ponte a punto de seguir este viaje conmigo, y a la gran obra disponte.

(Cervantes,1967, 68)

El maravilloso conocimiento de la Biblia le dio a Cervantes la posibilidad no solo de usar, sino de aplicar referencias bíblicas como alegorías simultáneamente con la connotación de filosofía hermética que también usa los términos bíblicos. 
Según Rafael Urbano, todos los nombres de las personas y lugares a los que se refiere Cervantes son alegorías y metáforas filosóficas, históricas, como: "el yelmo de Mambrino es decir, representa la Monarquía; los cabreros, la Iglesia; el traslado de los restos de San Juan de la Cruz; en la del cuerpo muerto; Iñigo de Loyola o el mismo Jesús” (Urbano, 2001, 388)

Pero mucho más excitante, como sabremos más adelante, Cervantes usó la misma alegoría con varias connotaciones simultáneamente para ocultar su significado real a la Inquisición en real.

\section{Discusión}

\subsection{Análisis de la influencia filosófica hermética en la obra La gitanilla de Cervantes.}

Es posible que Margarita no sea solo una alegoría de la belleza que es: "la preciosa margarita que había ganado", es decir, como maravillosa, pero preciosa margarita era un término hermético muy popular en la época de Cervantes en motivo de la versión impresa de Pretiosa Margarita que fue publicada en 1557. Se refiere a la obra de la propia piedra filosófica según su fuente, que fue escrita hacia 1330 por Petrus Bonus Margarita Preciosa Novela, como un texto hermético con extractos famosos de alquimistas españoles como Raymundo PseudoLulio.

Cervantes, en palabras de Preciosa, está contando alegóricamente no solo la historia de la Reina nuestra señora Margarita (Cervantes, 2015, p. 60), sino posiblemente sobre la referencia a la novela Pretiosa Margarita.

Los significados herméticos primarios, con connotaciones filosóficas herméticas, se encuentran realmente en La gitanilla de Cervantes. No puede ser coincidente, por lo que la filosofía hermética tiene unas determinadas reglas conceptuales, que no se pueden mezclar 
con ninguna otra cosa, por ej. los procesos de la gran obra como nigredo, albedo, rubedo que va en fila (Stoops, 201, 584)

La influencia de la filosofía hermética es evidente y hay algunas alegorías que no fueron determinadas previamente por los estudiosos, pero que pueden determinarse según significados secundarios. "Árbol precioso que tardó en dar fruto..." es la alegoría bíblica de Santa Anna, madre de la Virgen María en La Gitanilla (Cervantes, 2015, p. 57). Allí Cervantes está usando la misma alegoría con varias connotaciones simultáneamente para ocultar su significado real a la Inquisición en lo real, la primera es obviamente bíblica, la segunda es filosófica hermética, donde el árbol es utilizando como término para describir el hermetismo en sí.

Mostrar Dios grandezas

Sobre humano curso.

(Cervantes, 2015, p. 58)

Mostrar Dios grandezas, en filosofía hermética, es decir, como descubrir algo desconocido y sagrado que fue creado y conocido solo por Dios y sus adeptos. En razón según las palabras de Cristo: "Necios, el que hizo lo de afuera, ¿no hizo también lo de adentro” (Lucas 11:40) tiene una referencia a La Tabla de Esmeralda que es un texto críptico, atribuido al Hermes Trismegisto. Y en particular a la parte 2: "Lo que está más abajo es como lo que está arriba, y lo que está arriba es como lo que está abajo."

Por eso en la Pretiosa Margarita que es compendio de los escritos de los monjes medievales, se subrayaba la importancia de Dios en la filosofía hermética, y la elaboración de la piedra filosófica, que creían que podía salvar, curar y prolongar la vida como un Cristo que prometió volver salvar vidas de personas, por ej. Pretiosa Margarita por Petrus Bonus (1557), 43. Por lo tanto, especialmente la resurrección de Cristo fue la parte más importante en la filosofía hermética y alegóricamente tiene un significado del último nivel de la obra filosofal. Por tanto, es posible interpretar el remedio en forma filosófica de Trismegisto, como el remedio hermético: "Do van por remedio.” (Cervantes, 2015, p. 58) 
Según el Cervantes, que quiso dar alguna pista a sus palabras, eso también suena muy hermético: "verás cosas que se tocan de milagro, / Dios al frente y San Cristóbal gigante" (Cervantes, 2015, p. 92), “y sé que puedes con Dios” (Cervantes, 2015, p. 64).

Una frase es muy agradable, menciona el lenguaje de Dios, que se apunta al concepto alegórico para obtener el significado real del texto: "El dios parlero va en lenguas lisonjeras y amorosas" (Cervantes, 2015, p. 61)

Por ej.: "las gitanillas, y estábalas esperando como el agua de mayo" (Cervantes, 2015, p. 69), en este caso "las gitanillas" son alegóricamente una referencia al hermetismo porque el agua de mayo lexicalmente en esta filosofía tiene otro significado. El rocío o ros en latín es el famoso símbolo por excelencia de la piedra filosofal. Según el hermetismo es el agua con propiedades especiales de la primera materia del mundo y solo del rocío destilado en mayo es posible obtener la piedra filosofal. (Silva, 2013, 6)

Por supuesto que se puede decir que el texto de Cervantes es sólo una coincidencia, pero a medida que se puede analizar más a fondo, hay más posibles interpretaciones herméticas.

La parte más importante para interpretar la obra de Cervantes La gitanilla en su aspecto hermético es la mismísima la gitanilla, el texto que se describe a sí misma, a sus propias palabras, especialmente en canciones. Hay una alegoría hermética, qué espíritu fantástico tiene un léxico alquímico y significa una parte del espíritu o una hoja de la sustancia de la piedra filosofal: "Esta mi hermosura que tú dices que tengo, que la estimas sobre el sol y la encareces sobre el oro, ¿qué sé yo si de cerca te parecerá sombra, y tocada, cairás en que es de alquimia?" (Cervantes, 2015, p. 98)

Importante, que la frase de Preciosa sobre la alquimia enfatiza la posibilidad de interpretación a nivel del hermetismo, a pesar de la contradicción, como utilizar para ocultar el significado real del descubrimiento del valor con el toque de la piedra filosofal de la Inquisición de 
Cervantes. piedra filosofal: el sol, es decir, la metáfora hermética del oro, que se utilizó para obtener la piedra filosofal más cara.

Además, en la frase sobre Preciosa es obvia la referencia a la alquimia en real: "que un basilisco se cría en ti” (Cervantes, 2015, p. 67) Según el diccionario de alquimia, el basilisco simboliza el mercurio de los metales, que se fija y se convierte en oro o plata.

Así como en palabras de Margarita que también tiene epítetos del oro, está razonando y argumentando que: "Lo que me has dado te doy" (Cervantes, 2015, p. 63). De la misma manera que en la filosofía hermética que describe la multiplicación de la piedra filosofal: “...llovían en ella ochavos y cuartos como piedras a tablado.” (Cervantes, 2015, p. 59)

Curiosa es la posible interpretación de la frase: "llovían en ella ochavos y cuartos como piedras a tablado" (Cervantes, 2015, p. 59) que subrayando la riqueza preciosa con la juega de palabras "piedras a tablado" como La Tabla de Esmeralda que es un texto hermético. Esmeralda es una piedra, por eso posible interpretar como La Tabla de piedra filosofal. Más importante descripción de Andrés como: "los átomos del sol se pega" (Cervantes, 2015, p. 116).

En estrofa sobre Júpiter que, en filosofía hermética, significa el símbolo del estaño. (Poisson, p. 84) Cervantes usó figuras literarias como alegorías, símbolos con asociación intelectual, que tiene posible sentido en la filosofía hermética. Por ej. Júpiter que según vocabulario hermético significa el símbolo del estaño (Poisson, p. 84): “va Júpiter; que no hay cosa/difícil a la privanza/fundada en prudentes obras." (Cervantes, 2015, p. 61) En el contexto de Júpiter es importante la segunda frase sobre obras prudentes con interpretación alquímica, que tiene un significado de las etapas de la gran obra en filosofía hermética.

"Corona del donaire" es una repetición contigua de las palabras de Andrés y Clemente en una canción de La gitanilla y da alguna sugerencia de la importancia de la coronación, que en hermetismo es muy frecuente y significa la perfección metálica, especialmente en el texto de 
Margarita pretiosa, donde coronación sigue la transmutación con símbolo de corona sobre la cabeza. (Poisson, p. 83):

Andrés: $<\ldots>$ corona del donaire, honor del brío.

Clemente: Corona del donaire, honor del brío.

(Cervantes, 2015, p. 118)

Atrayente es el final de la novela La gitanilla, porque el símbolo más importante para obtener piedra filosófica es la boda. Los alquimistas hablan sobre la boda de elementos como conjunción del 'rey' que es el azufre filosófico y la 'reina' que es el mercurio filosófico en un matrimonio alquímico por perfección del elixir. En esta parte posible interpretación filosófica, en razón en el texto de Cervantes Preciosa ha obtenido algún tipo de metamorfosis, que le da a Andrés para casarse con ella: "Preciosa sea vuestra legítima consorte" (Cervantes, 2015, p. 133). Curiosas son las palabras de Andreas sobre compararlo con monarca del mundo también: "Pues Preciosa no ha querido contenerse en los límites del silencio, y ha descubierto quién soy, aunque esa buena dicha me hallara hecho monarca del mundo" (Cervantes, 2015, p. 133).

\subsection{El contexto de las alegorías de la protagonista Margarita y el protagonista Andrés en la obra La gitanilla de Cervantes según la influencia filosofía hermética}

La protagonista, Preciosa, según el texto, es una joven gitana que se describe como una hermosa niña de ojos verdes y rubia. Es espiritualmente consciente de sus cualidades morales y tiene grandes virtudes a través de sus palabras y acciones: como la honestidad y la inteligencia, está bien argumentada, canta y baila con gracia especial, pero discreta pero no deshonrosa, e incluso reservada, inflexible.

En el caso de Preciosa, se revela su personalidad oculta, es decir, como una alegoría de la piedra filosofal a otros seguidores. Su origen está oculto no solo para ella sino también para los demás, hasta un punto de inflexión en la historia La gitanilla adquiere importantes 
conocimientos sobre su personalidad, solo que en la catarsis de la misma manera que el adepto adquiere conocimientos sobre algo noble y sagrado como la piedra filosofal: "por lo que de piedra tienes te llama el mundo Preciosa. Desta verdad me asegura esto, como en ti verás;" (Cervantes, 2015, p. 67)

Curiosamente, en La gitanilla Cervantes utilizó la agnición como "reconocimiento", derivado del griego antiguo, es decir, como recurso narrativo, que consiste en el reconocimiento de los personajes principales. Así, se puede explicar a través del prisma de filosofía hermética, como el descubrimiento y la revelación de la piedra filosofal, en razón que el otro nombre de la gitana es Preciosa, Cervantes utilizó precisamente el término como referencia a la obra hermética medieval Preciosa.

Según Ricoeur: "No hay conocimiento simbólico salvo cuando es imposible comprender directamente el concepto y cuando la dirección hacia el concepto es indicada indirectamente por la significación secundaria de una significación primaria” (Ricoeur, 2001, 69).

Es probable, como hipótesis, que Cervantes utilice las alegorías alquímicas con un juego de palabras cuando menciona la descripción de la gitana. Por ej.: "Y, finalmente, la abuela conoció el tesoro que en la nieta tenía” (Cervantes, 2015, p. 56).

Especialmente cuando Cervantes describe algunas características de Preciosa comparándolas con plata, o como perla, que también se utilizan en gran obra de piedra filosofal: “¡Por Dios, tan linda es la gitanilla que hecha de plata o de alcorza no podría ser mejor!” (Cervantes, 2015, p. 70), "Esta perla que nos diste, $<\ldots>$, única y sola" (Cervantes, 2015, p. 62).

Más importante que en latín perla es margarita, que también es un argumento más a la hipótesis de que Preciosa tiene una referencia directa a Margarita pretiosa escrita en latín. Apreciable, como se nota la vieja gitana Preciosa es muy inteligente: “¡mira que dices cosas que no las diría un colegial de Salamanca! < ..> te estoy escuchando como a una persona espiritada, que habla latín sin saberlo.” (Cervantes, 2015, p. 80) Evidentemente se destaca la 
importancia de la referencia a la lengua latina, así como a la referencia a la Universidad de Salamanca y posible referencia como respeto por Cervantes al profesor de la Universidad Salamanca Fray Luis de León seguidor de la filosofía Hermética (Cervantes:1967, 751).

Además, Cervantes utilizó alegorías sobre la protagonista Margarita con juegos de palabras, por ej. "Rosamunda-rosa inmunda", es decir, rosa asquerosa, pero "Rosamunda" se puede explicar con el calambur como rosa del mundo, que es en realidad el término hermético de la piedra filosófica. La gitanilla, como personaje, desarrolla talentos para cantar versos, generalmente romances, zarabandas, villancicos, cuerdas. Se le da a Cervantes genialmente posibilidad de añadir este lugar en su trabajo para escribir sobre la filosofía hermética mediante el uso de composiciones poéticas, especialmente habladas por Preciosa por ej.: "las de plata o de oro son mejores;" (Cervantes, 2015, p. 70).

Como se describe en un importante verso sobre Preciosa enfatizando la importancia de los poemas: "tus hechizos son de más fuerzas y más veras" (Cervantes, 2015, p. 68). Preciosa es rica: "Nunca se apartaba della la gitana vieja, hecha su Argos, temerosa no se la despabilasen y traspusiesen”. (Cervantes, 2015, p. 59) Según el diccionario de alquimia Argos es un término con significado de los colores de la obra del filósofo como etapas en la época medieval (Anónimo, 2020, 13).

Especialmente, en el conocimiento de algo sagrado, como un adepto de la filosofía sagrada y todas sus composiciones poéticas tienen tales notas, por lo tanto, cantaba romances con: “espiritillo fantástico acá dentro, que a grandes cosas me lleva” (Cervantes, 2015, p. 78). Como decía el paje, que la poesía tiene un rol muy cierto en la Gitanilla: "Hase de usar de la poesía como de una joya preciosísima, cuyo dueño no la trae cada día, ni la muestra a todas gentes, ni a cada paso, sino cuando convenga y sea razón que la muestre $<\ldots>$ quisiera tener para daros las riquezas de Midas" (Cervantes, 2015, p. 85). Es decir, como el tesoro del conocimiento sagrado. 
Según la estrofa sobre "los himnos", la poesía tiene una conexión directa para interpretar los términos que se utilizan también en astronomía y alquimia: "himnos y voces que muestran que está en el suelo la Gloria. <..> volvió a su punto este cielo y esfera maravillosa.” (Cervantes, 2015, p. 64) Según el diccionario de alquimia, el término esfera es unidad de la materia, el término cielo es el vaso de los sabios (Poisson, p. 85).

Incluso en las palabras de Preciosa sobre sí mismo, se puede encontrar cierto subtexto hipotético de la alegoría de la piedra filosofal y la alquimia: "En este mi bajo cobre" (Cervantes, 2015, p. 119). Es posible que tiene referencia a cobre de mercurio es lo que rubifica, según el manuscrito 2151 de la Biblioteca Nacional.

Andrés, como el protagonista también se llamaba Don Juan antes de ser gitano, en realidad es una persona muy noble, enamorado de la gitanilla y dispuesto a hacer todo lo posible para conseguir y quedarse con su amor. Es directo en su alma, se respetaba a sí mismo y a su virginidad, decidió ser parte de los gitanos durante dos años. Para el protagonista Andrés Cervantes utiliza las figuras estilísticas, por ej. retruécano: "No fue Andrés Caballero, sino don Juan, y un caballero". Pero más utiliza la ironía, que expresa lo contrario de lo que dice y es más frecuente en La Gitanilla como figura estilística, con posibles referencias a la filosofía hermética y la alquimia: "la aceda respuesta de Andrés..." (Cervantes, 2015, p. 120) o “cabello de oro" (Cervantes, 2015, p. 69).

Maravilloso que Cervantes compare a Andrés con águila, según el diccionario de alquimia, el águila simboliza la volatilización y también los ácidos utilizados en la gran obra (Poisson, p. 82). También, utiliza ironía con posible juego de palabras y sustitución homofónica: "que salgas un águila en el oficio; $<\ldots>$ De azotes he visto yo volver a algunos désos vacíos" (Cervantes, 2015, p. 100). En este caso azotes suena a azoth, que es una de dos partes del cuerpo coagulado, que servirá de azoth para lavar y modificar a la otra según el diccionario de alquimia. 
Lo más importante es cuando Cervantes compara a Andrés con átomos: "los átomos del sol se pegan" (Cervantes, 2015, p. 116) con referencia a filosofía hermética, donde el sol es el oro ordinario o preparado para la Obra de piedra filosófica. (Poisson, p. 85)

\subsection{El contexto de las otras alegorías en la obra La gitanilla de Cervantes según la influencia filosófica hermética: las plantas, los planetas y otras cosas}

Cervantes utilizó una misma alegoría con varias connotaciones al mismo tiempo para ocultar su significado real. Es posible que, para evitar problemas con la Inquisición, Cervantes inventara en sus obras el uso simultáneo de varios tipos de alegorías para ocultar el significado hermético. Por ejemplo, una alegoría muy clara con una connotación histórica puede tener una definición diferente como alegoría secundaria, "la Reina nuestra señora Margarita ... A un lado lleva el sol de Austria, /Al otro la tierna aurora" (Cervantes, 2015: 60)

Esta frase se refiere al rey de España en ese momento, Felipe III de la dinastía austriaca de los Habsburgo; tierna Aurora - hija de tres años de Felipe III, infanta Anna. (Cervantes, 1914, 13)

Pero, por otro lado, Aurora según el hermetismo es un planeta de cobre, el otro nombre de Venus. (Poisson, p. 85)

La siguiente frase de Cervantes también contiene palabras que pueden interpretarse como alquímicas:

A sus espaldas le sigue

Un lucero, que á deshora.

salió, la noche del día

que el cielo y la tierra lloran.

(Cervantes, 2015, p. 60)

Donde el cielo es un vaso de los sabios (Poisson, p. 84). La tierra según diccionario de alquimia es metal calcinado, último principio pasivo que siempre retiene obstinadamente 
algún espíritu, nunca es pura o materia que llena la parte del recipiente (Anónimo, 2020, 44). El cielo y la tierra lloran podemos analizar como la lluvia, que es símbolo de condensación, color blanco (albificación). (Poisson, p. 84)

Es muy provechoso que otras frases de la novela de Cervantes se ocupen de otro tipo de elementos, especialmente metales, que se utilizan en la filosofía hermética:

Aquí el anciano Saturno

La barba pule y remoza,

$\mathrm{Y}$ aunque es tardo, va ligero.

(Cervantes, 2015, p. 61)

Saturno según la filosofía hermética es un símbolo del plomo. Figura también el color negro, porque se usa generalmente en la putrefacción con otros metales. Según la filosofía hermética, Cupido es un símbolo de mercurio que usa junto con otros metales para la piedra filosofal. Interesante, que el mercurio se usa con una proporción diferente para cada metal, porque “Cupido en cifras varias." (Poisson, p. 84):

Y Cupido en cifras varias.

que rubíes y perlas bordan.

(Cervantes, 2015, p. 61)

Es la estrofa sobre Marte, que es un símbolo del fierro según el diccionario de alquimia. (Poisson, p. 84):

Allí va el furioso Marte

en la persona curiosa

(Cervantes, 2015, p. 61)

En esta estrofa se menciona a Júpiter que, en filosofía hermética, significa el símbolo del estaño. (Poisson, p. 84) Y la casa del sol significa el metal de oro y los procesos de transmutación. (Poisson, p. 85): 
Junto a la casa del Sol

va Júpiter; que no hay cosa

difícil a la privanza

fundada en prudentes obras.

(Cervantes, 2015, p. 61)

Fundada en prudentes obras en el contexto alquímico tiene un significado de las etapas de la gran obra para la piedra filosofal.

Va la Luna en las mejillas

de una y otra humana diosa;

(Cervantes, 2015, p. 61)

Según el diccionario de alquimia, la luna es la madre del rey, es un metal plateado preparado para el trabajo filosófico. (Poisson, p. 84)

Venus casta, en la belleza

de las que este cielo forman.

(Cervantes, 2015, p. 61)

Venus es un símbolo del cobre, cuyos elementos forman los gases en vaso de los sabios, que es hermética connotación del cielo. (Poisson, p. 85)

“Pequeñuelos Ganimedes” (Cervantes, 2015, p. 61): Ganimedes se utilizaron en astronomía y alquimia en manuscritos medievales por ej. en manuscrito Cicero Aratea de Reims, alrededor de 820-840, que, situado en la Biblioteca Británica de Londres.

La influencia de la literatura romana de Virgilio es obvia, pero fascinante alguna connotación filosófica lo que exactamente "me prometió a mí un cierto poeta."

Según Las Moradas Filosofales por Fulcanelli, el agua de Estigia es un término de filosofía hermética. (Fulcanelli, 2000, 159) Por eso es posible interpretar la frase: “prometerá las alas 
de Mercurio y los rayos de Júpiter, como me prometió a mí un cierto poeta, y juraba por la laguna Estigia" (Cervantes, 2015, p. 99) como un intertexto de la filosofía hermética.

Además, según el diccionario de alquimia, atlante se representa a sí mismo ante la materia volátil de la gran obra, solo detenida por materia fija con referencia a hermetismo. (Anónimo,2020, 13)

Humano Atlante, se encorva

al peso de tantos reinos.

(Cervantes, 2015, p. 63)

La frase: "y así, determinó el águila vieja sacar a volar su aguilucho y enseñarle a vivir por sus uñas” (Cervantes, 2015, p. 56), como la siguiente frase es posible interpretar y analizar en el concepto de filosofía hermética, por ej.:

Vivas, ¡oh blanca paloma!

que nos has de dar por crías

águilas de dos coronas,

para ahuyentar de los aires

las de rapiña furiosas;

para cubrir con sus alas

a las virtudes medrosas.

(Cervantes, 2015, p. 62)

Según Stoops, los alquimistas tienen una gradación en fila durante la Gran Obra. La más importante es la primera etapa: nigredo, la segunda etapa es albedo, la tercera etapa es rubedo (Stoops,2016, 584).

En este texto de Cervantes es posible referirse a la gradación del proceso, particularmente al primer nigredo de interpretación de águilas, porque según el diccionario de alquimia, el águila simboliza la volatilización y también los ácidos utilizados en la gran obra. Dos águilas tienen 
la misma significación. La paloma simboliza el color blanco, como la siguiente etapa del proceso (Poisson, p. 82).

La frase: "Eres paloma sin hiel" (Cervantes, 2015, p. 71) es posible interpretar como referencia a la segunda etapa del proceso como un albedo con purificación de piedra filosofal.

La corona es un símbolo de la alquimia, de la perfección metálica. En la Margarita pretiosa, los seis metales son al comienzo presentados como esclavos, cabeza descubierta a los pies del rey, del oro, pero después de su transmutación, tienen una corona sobre la cabeza (Poisson, p. $83)$.

Cuando Cervantes menciona en La Gitanilla: "templo del Fénix santo" (Cervantes, 2015, p. 63) es posible interpretar como la tercera estadía del proceso, porque el fénix es un símbolo del color rojo en la piedra filosofal (Poisson, p. 84).

Es importante destacar la Buenaventura de Preciosa, y su interpretación según la filosofía hermética: “como leona de Orán..." (Cervantes, 2015, p. 72) es bastante posible, que leona sea un símbolo del azufre de los filósofos (Poisson, p. 84).

El interés de Cervantes por las plantas es muy evidente en La gitanilla, hay numerosas menciones de plantas, algunas de ellas son populares como rosa, alcornoque, viñas, uvas, romero verde, olmo y menos conocidas, como tártago y juncia. A veces es la alegoría de amor: Fecunda vid, crece, sube, abraza y toca

el olmo felice tuyo que mil siglos te hagan sombra

(Cervantes, 2015, p. 62)

La tendencia con la que Cervantes usó las plantas en esta obra demuestra que no es un símil, no es una ironía, no es una dilogía, un epíteto y no tiene nada con rima. Por lo tanto, usar tal cantidad de varias plantas, generalmente una vez en el trabajo completo La gitanilla no tiene mucho sentido. Analizando estas plantas con connotación de filosofía hermética, todas estas 
plantas fueron utilizadas por algunos filósofos para obtener la piedra filosofal. Por ejemplo, en las obras de Lulio, que fue mencionado en Pretiosa Margarita (Lulio, 1507, p39-55).

\section{Resultados}

Los resultados de este estudio sugieren que la obra de Cervantes la Gitanilla puede tener algunas referencias a la filosofía hermética. Por supuesto, se puede suponer que es solo una coincidencia, pero este trabajo se basa en las palabras de Cervantes sobre sus sentimientos filosóficos a Fray Luis de León que fue seguidor de la filosofía Hermética y la estaba enseñando en la Universidad de Salamanca.

Esta cierta investigación está apoyada por otras investigaciones de otras novelas de Cervantes por ej. Castillo Martos y Stoops. La frecuencia de palabras que pueden interpretarse como alegorías herméticas con términos alquímicos es muy alta. El concepto de mencionar etapas de Grand Obra nigredo, albedo, rubedo se conserva en una fila. Se utiliza alegorías conocidas en la alquimia medieval como águilas para nigredo que simboliza la volatilización, La paloma simboliza el proceso del albedo, Phoenix simboliza el proceso del rubedo. Cervantes usó términos de los planetas y los nombres de diferentes plantas que también se pueden interpretar en la filosofía hermética.

\section{Conclusiones}

La parte más importante para interpretar la obra de Cervantes La gitanilla en su aspecto hermético es la mismísima la gitanilla, el texto que se describe a sí misma, a sus propias palabras, especialmente en canciones.

Es posible que Cervantes haya utilizado varias alegorías en unas, por ej. junto con los significados históricos o bíblicos de las alegorías, se utilizó también hermético, especialmente para ocultar el significado real de los textos de la Inquisición. 
Importante mencionar el nombre mismo de Gitanilla, Preciosa, que fue muy escuchado y popular en la época de Oro gracias a la obra republicada de Pretiosa Margarita que fue publicada en 1557, y que se refiere a la obra de la propia piedra filosófica según su fuente, que fue escrita hacia 1330 por Petrus Bonus, como un texto hermético con extractos famosos de alquimistas españoles como Raymundo Pseudo-Lulio.

Cervantes utiliza el nombre de Margarita en las Canciones de Preciosa para describir pensamientos filosóficos, sean herméticos o no, pero da algunos motivos para subrayar la posibilidad de interpretarlos como alegorías herméticas. Por lo tanto, las alegorías más difíciles son posibles de reconocer cuando existe la posibilidad de concepto que se indica indirectamente por algún significado secundario de un significado primario particular. Importante, que la interpretación de las alegorías depende del nivel de los lectores y su comprensión de los significados alegóricos.

\section{Referencias}

Alcantara Mejia, J.R., El Pensamiento De Fray Luis De León En La Obra De Cervantes, 1998

Anónimo, Diccionario De Alquimia. Madrid 2020

Aristóteles, Poética. Traducción del griego, prólogo y notas de José Goya y Muñían. Buenos Aires 1948

Barbaro, E., In Dioscoridem Corollarii Libri Quinque Non Ante Impressi, S.n. [gregoriorum Fratrum Officina],Venetiis, V, F. 1516, 100v

Belenguer, J. V., La Alquimia En Las Metáforas Cervantinas. Madrid 2020

Chaide, M. De, Libro De La Conversión De La Magdalena, Part, IV, Valencia 1583

Volumen 2. Número 1. Enero - Junio 2022 
Brown, D, God and mystery in words. Oxford University Press Inc., 2008

Bustamante,C. Arí:Análisis Lingüistico $Y$ Evaluación De Las Traducciones De Huasipungo. Yala 2004

Byrne, S., Cuestionamiento Del Hermetismo Ficiniano En Dos Manuscritos Del Siglo XV: El Escorial Y El Burgo De Osma. Londres 2012

Cervantes, M. De, Don Quijote de la Mancha, Tomo 2. Chile 1990

Cervantes, M. De, Novelas Ejemplares, Obras Completas De Cervantes: Tomo I, Imprenta De Don Manuel Rivadeneyra, Madrid 1914

Cervantes, M. De, Obras Completas, Ed. Ángel Prat, Madrid, Aguilar. 1967

Cervantes, M. De, Ocho novelas ejemplares. Madrid 2015

Cirlot, J. E., Diccionario De Símbolos. Madrid 2018

Dyonysious, Areopagita La Jerarquía De Los Ángeles Y La Iglesia. Madrid 1955

Eco, U., Los Límites De La Interpretación. Madrid 1992

Fulcanelli, Las Moradas Filosofales. Madrid 2000

García Verdugo, C., Alquimia Y Atomismo En El Quijote. Madrid 2008

Gladyševa, A., «Voynich Manuscript - Analysis Of The Codification Algorithm With The Encryption Methods Known In The Medieval Time And Results Of The Marginalies That Were 
Not Encrypted». Revista Científica Arbitrada De La Fundación Menteclara, Vol. 5 (128), 2020 DOI: https://doi.org/10.32351/rca.v5.128

https://www.researchgate.net/publication/338416501_analysis_coding_algorithm_with_the_ known_in_medieval_period_methods_of_ciphering_and_results_of_the_unencrypted_margi nalia_of_the_voynich_manuscript_manuscrito_de_voynich_-_analisis_del_algoritmo_de_c [accessed Jun 30 2021].

González, A. M., Alquimia Y Alegoría En El Contexto Medieval. Madrid 2007

Hanegraaff, W. J. How Hermetic Was Renaissance Hermetism? In Aries - Journal For The Study Of Western Esotericism 15, Leiden: Koninklijke Brill, 2015, pp.179-209

Herrero, J., La metáfora del libro en cervantes. Alicante, Biblioteca Virtual Miguel de Cervantes, 2016

Initiates, Three, The Kybalion: The Hermetic Philosophy Of Ancient Egypt And Greece. Chicago: The Yogi Publication Society, 1908.

Khunrath, H., Anfiteatro Sapientiae Aeternae, Londres 1609

Lulio, R., Ars Magna, La Biblioteca Del Escorial, Madrid 1400

Magrinyà Badiella, C., Post Tenebras Spero Lucem. Alquimia Y Ritos En El Quijote Y Otras Obras Cervantinas. 2014. Uppsala 2014

Morales, R., Glosario De Alusiones A Vegetales En Las Obras Completas De Cervantes. Madrid 2014

Morales Valverde, R., Flora Literaria Del Quijote. Madrid 2005 
Petrus Bonus Margarita Preciosa Novela. Madrid 1330

Ricoeur, P., "La Metáfora Y El Símbolo" En Teoría De La Interpretación. Discurso Y Excedencia De Sentido, Siglo XXI, México 2001

Rodríguez M., F. Felipe II Y La Alquimia. Madrid 1800

Romera Castillo, J., Textos Literarios Y Enseñanza Del Español, Madrid, Uned. 2013

Silva, L., Egrégora Alquímica Con Vasilius, Madrid. 2013

Stoops, R. M., Nigredo, Albedo, Rubedo Y Otras Alegorías Alquímicas. En La Fuerza De La Sangre, Una Novela Ejemplar De Miguel De Cervantes, Madrid 2016

The New Oxford Annotated Bible. Edited by Michael D. Coogan, Oxford University Press, 2007.

Touwaide, A., Plants In The Works Of Cervantes. Economic Botany, Estados Unidos 2006

Ullén, M., Dante In Paradise New Literary History, Londres 2001, p177-199 
REVISTA INTERNACIONAL DE FILOSOFÍA TEÓRICA Y PRÁCTICA 